\section{World Glaucoma Day, 6 March 2008: tackling glaucoma internationally}

Eye advance online publication, 15 February 2008; doi:10.1038/eye.2008.12

We have all heard many times that 'glaucoma is the second most common treatable cause of blindness worldwide'. Glaucoma is a significant public health concern, being the leading cause of irreversible vision loss and consistently ranking among the leading causes of blindness in virtually every nation. ${ }^{1}$ In developing countries, cataract is the leading cause of blindness. In developed countries, the leading cause of blindness is age-related macular degeneration (AMD). There is, however, a fundamental difference between these two diseases and glaucoma: their high rank as causes of blindness is due to structural reasons that are hard to address (limited access to surgical infrastructure for cataract; lack of an effective preventive treatment for AMD), whereas in the case of glaucoma the main reason is low awareness of the disease and its implications. Indeed, it is estimated that only one-half of those affected with glaucoma in developed nations are aware that they have the disease, ${ }^{2}$ while as many as $90 \%$ or more of people with glaucoma in underdeveloped countries are unaware of having the disease or have even heard of glaucoma. Despite our better understanding of risk factors for glaucoma, we have yet to see an improvement in these numbers. Worse, although glaucoma occurs in all age groups, it is more common in older adults, and with an ageing population, estimates of glaucoma prevalence are increasing. It has been predicted that by 2020 , 79.6 million people worldwide will have glaucoma, 11.2 million of whom will be bilaterally blind ${ }^{1}$, up from the current 4.5 million. ${ }^{3}$

Recent years have seen considerable progress in the diagnosis and treatment of glaucoma. Technological advances in optic and retinal nerve fibre layer imaging and visual field testing make it possible to diagnose glaucoma at earlier stages, when treatment has a better prognosis. Medical treatment is available and effective for controlling glaucoma for most patients, ${ }^{4}$ while for those who have uncontrolled disease, laser and surgical interventions are often successful.

Optic nerve damage and visual field damage are irreversible. As damage progresses gradually, often unnoticed by the patient, early detection and treatment are of paramount importance to prevent blindness. For individuals with known risk factors for glaucoma, particularly elevated intraocular pressure, increasing age, African descent, family history of glaucoma, vasospasm, low blood pressure, and high myopia, the importance of routine examinations cannot be understated. Also, despite strong evidence that lowering intraocular pressure can delay the onset and progression of glaucoma, ${ }^{5-7}$ reported rates of noncompliance with glaucoma therapy range from 5 to as high as $80 \% .^{8}$ This high variability results from different definitions for noncompliance and the way it is measured.

\section{World Glaucoma Day}

The year 2008 is a pivotal one for glaucoma awareness. To combat the ignorance that leads to so much loss of vision, the World Glaucoma Association and the World Glaucoma Patient Association have joined forces to launch a global initiative aimed at raising awareness of glaucoma through an annual World Glaucoma Day (WGD). As a way to jumpstart awareness activities and to enlist the active support of governments, eye care professionals, and patient support groups in many nations, the 6th of March 2008 has been selected for the first WGD. Rather than have a single large event held in conjunction with a major conference, WGD will consist of the sum total of local,
${ }^{1}$ Department of Ophthalmology, University of Toronto, Toronto, Canada

${ }^{2}$ Department of Ophthalmology, University of Sydney, Sydney, Australia

${ }^{3}$ Athens Institute of Ophthalmology, Athens, Greece

${ }^{4}$ Einhorn Clinical Research Center, New York Eye and Ear Infirmary, New York, USA

Correspondence:

GN Lambrou,

Athens Institute of

Ophthalmology,

Agias Barbaras 61,

Athens,

Halandri 15231,

Greece

Tel: + 30210722 2722;

Fax: + 302107222747 .

E-mail: gnlambrou@

hotmail.com or

george@lambrou.eu 
regional, and national initiatives and events organized by willing groups and individuals around the world.

These activities will include media campaigns; official recognition (three countries will issue commemorative stamps and a delegation from the American Glaucoma Society will visit the US Congress); public-oriented events (eg, screenings in public places); and institutional events (open-door days at eye clinics and universities, with lectures addressed to professional and lay audiences). All these events, together with supporting material, general information on the disease, and useful links, are listed at www.wgday.net.

The public needs to know that there are means for detecting and treating glaucoma and that sight can be saved. People should be made aware of the insidious nature of glaucoma and the importance of compliance with treatment and follow-up to minimize their risk of visual loss. People with glaucoma need to inform family members, so that they too can be screened. Health care providers, together with their government, should promote public awareness campaigns encouraging regular eye examinations, especially for those with known risk factors. Eye-care professionals should take the lead by writing articles for local newspapers, contacting radio stations, or organizing public meetings on glaucoma. Earlier diagnosis and treatment will reduce visual disability, improve patients' quality of life, and decrease the overall costs of treatment. The World Glaucoma Association has set a goal of reducing the undiagnosed rate of glaucoma from 50 to 'no more than $20 \%$ by 2020 '. This goal is attainable if all parties work together to increase awareness of glaucoma, both among the public as well as among health care providers, and if we all ensure quality eye examinations are available worldwide.

\section{Your participation}

Each of us can help to make this a day to remember. The possibilities abound. Groups and individuals around the world have volunteered to organize events of the types described. Others have come up with original ideas: a national ophthalmology journal will publish a special glaucoma issue; other scientific journals will publish editorials on glaucoma; and a group of volunteers will run in the Geneva annual marathon under the WGD colours. In Latin America, a tongue-in-cheek movie has been produced to remind patients humorously that compliance with therapy is the best way to keep the 'sneak thief of sight' at bay.

The success of WGD also depends on eye-care professionals actively participating at a national level, and by developing local strategies to achieve this goal. Every journey begins with a small step, but it is the cumulative number of steps that will determine how far we will go. As WGD approaches, take that first step: ask yourself 'What can I do?' and make this campaign a success.

The possibilities are endless, but the success of the day will depend not only on the number and attendance of events organized globally, but also on their visibility. So, to maximize the impact of this initiative, please take a moment to visit either www.wgday.org or www.wgday.net and fill out the Intent Form (under 'Be a Part of It'), and tell the world how you will contribute to the success of the first-ever WGD.

\section{References}

1 Quigley HA, Broman AT. The number of people with glaucoma worldwide in 2010 and 2020. Br J Ophthalmol 2006; 90: $262-267$.

2 Sommer A, Tielsch JM, Katz J, Quigley HA, Gottsch JD, Javitt J et al. Relationship between intraocular pressure and primary open angle glaucoma among white and black Americans. The Baltimore Eye Survey. Arch Ophthalmol 1991; 109: 1090-1095.

3 World Health Organization. data from www.who.int/ blindness/causes/priority/en/ (accessed 10 December 2007).

4 Feiner L, Piltz-Seymour J. Collaborative Initial Glaucoma Treatment Study: a summary of results to date. Curr Opin Ophthalmol 2003; 14: 106-111.

5 Heijl A, Leske MC, Bengtsson B, Hyman L, Bengtsson B, Hussein M, Early Manifest Glaucoma Trial Group. Reduction of intraocular pressure and glaucoma progression: results from the Early Manifest Glaucoma Trial. Arch Ophthalmol 2002; 120: 1268-1279.

6 AGIS Investigators. 7. The relationship between control of intraocular pressure and visual field deterioration. $A m$ J Ophthalmol 2000; 130: 429-440.

7 Kass MA, Heuer DK, Higginbotham EJ, Johnson CA, Keltner JL, Miller JP, et al., The Ocular Hypertension Treatment Study. A randomized trial determines that topical ocular hypotensive medication delays or prevents the onset of primary open-angle glaucoma. Arch Ophthalmol 2002; 120: 701-713.

8 Olthoff CM, Schouten JS, van de Borne BW, Webers CA. Noncompliance with ocular hypotensive treatment in patients with glaucoma or ocular hypertension: an evidencebased review. Ophthalmology 2005; 112: 953-961. 